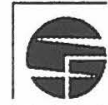

IIASA

Global Bioenergy Potentials

Through 2050

Günther Fischer

Leo Schrattenholzer

RR-01-09

June 2001 



\section{Global Bioenergy Potentials Through 2050}

Günther Fischer

Leo Schrattenholzer

RR-01-09

June 2001

Reprinted from Biomass and Bioenergy, 20 (2001) 151-159. 
Research Reports, which record research conducted at IIASA, are independently reviewed before publication. Views or opinions expressed herein do not necessarily represent those of the Institute, its National Member Organizations, or other organizations supporting the work.

Reprinted with permission from Biomass and Bioenergy, 20 (2001) 151-159.

Copyright (C) 2001 Elsevier Science

All rights reserved. No part of this publication may be reproduced or transmitted in any form or by any means, electronic or mechanical, including photocopy, recording, or any information storage or retrieval system, without permission in writing from the copyright holder. 


\title{
Global bioenergy potentials through 2050
}

\author{
Günther Fischer, Leo Schrattenholzer* \\ International Institute for Applied Systems Analysis, Schlossplatz 1, A-2361 Laxenburg, Austria \\ Received 31 January 2000; received in revised form 16 August 2000; accepted 30 September 2000
}

\begin{abstract}
Estimates of world regional potentials of the sustainable use of biomass for energy uses through the year 2050 are presented. The estimated potentials are consistent with scenarios of agricultural production and land use developed at the International Institute for Applied Systems Analysis, Austria. They thus avoid inconsistent land use, in particular conflicts between the agricultural and bioenergy land use. As an illustration of the circumstances under which a large part of this potential could be used in practice, a global energy scenario with high economic growth and low greenhouse gas emissions, developed by IIASA and the World Energy Council is summarised. In that scenario, bioenergy supplies $15 \%$ of global primary energy by 2050. Our estimation method is transparent and reproducible. A computer program to repeat the calculation of the estimates with possibly changed assumptions is available on request. (C) 2001 Elsevier Science Ltd. All rights reserved.
\end{abstract}

Keywords: Biomass energy; Global energy scenarios; Global agricultural scenarios

\section{Introduction}

Bioenergy is a renewable source of primary energy, and its sustainable use does not emit carbon dioxide. The increased use of this energy source could therefore contribute to achieving the objectives of the framework convention on climate change (FCCC) to stabilise atmospheric concentrations of greenhouse gases below dangerous levels. In assessing the possible degree to which bioenergy use could contribute to achieving this objective, the question about the global potential of bioenergy arises. Since a major input into bioenergy production is land, competition with food production is an important aspect determining the global bioenergy potential.

\footnotetext{
* Corresponding author. Tel.: +43-2236-807; fax: +43-223671313.

E-mail address: leo@iiasa.ac.at (L. Schrattenholzer).
}

Estimates of the global potential of bioenergy for primary energy uses through the year 2050 are presented. These estimates are consistent with land-use changes in a global scenario of agricultural development, that is, with requirements for arable land and with agricultural production as projected by IIASA's world food system model $[1,13]$. To illustrate the possible role of this potential in supplying the world's energy needs through the year 2050, results of a global scenario, published by Nakićenović et al. [2], which features high shares of bioenergy are summarised.

Potentials of renewable energy can be theoretical, technical, or economic. Each of the first two categories comprise the one immediately following it, so that the three categories are of decreasing magnitude. The theoretical potential is determined primarily by natural conditions and describes the amount of biomatter that could grow annually. The technical potential depends 


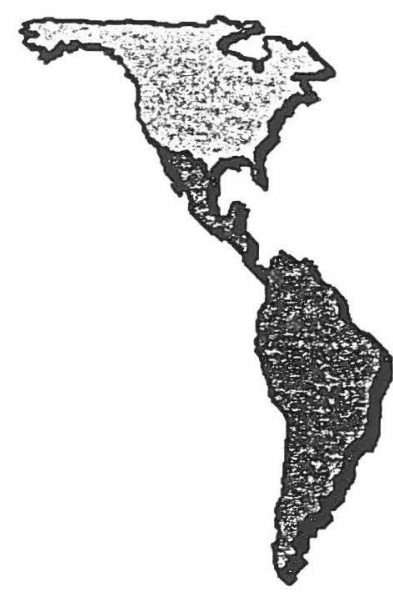

1 NAM North America

2 LAM Latin America \& the Caribbean

3 WEU Western Europe

4 EEU Central \& Eastern Europe

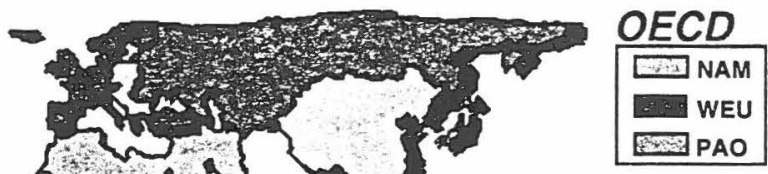

REFS

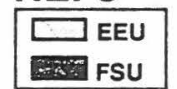

DCs

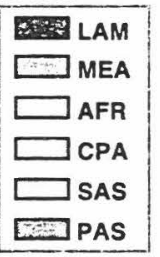

5 FSU Former Soviet Union

6 MEA Middle East \& North Africa 9 SAS South Asia

7 AFR Sub-Saharan Africa

10 PAS Other Pacific Asia

8 CPA Centrally Planned Asia \& China 11 PAO Pacific OECD

Fig. 1. Eleven world regions [2].

on the available technologies and therefore changes as technology progresses. The economic potential is the most variable because economic conditions vary, sometimes drastically, over time. For instance, forests in remote locations are part of the technical potential of renewable energy, but may not be suitable for exploitation due to high access costs. In our analysis, this is accounted for by the so-called accessibility factors. The estimates reported here do take into account economic criteria, and allow for the possibility of gradually changing economic conditions in future.

Utilisation costs could, for example, decrease in the future as a result of technological progress, which could increase yields per unit of land, increase efficiencies of processes converting biomass into useful energy, and lead to novel end-use technologies. In comparison with fossil fuels, relative costs of bioenergy utilisation could also decrease as a consequence of policies penalising the net emission of greenhouse gases. The global energy supply scenario summarised below is one in which utilisation costs of bioenergy develop favourably relative to fossil fuels. Therefore, it describes a case of a relatively large economic bioenergy potential.

\section{Bioenergy potentials in five categories}

The estimations include all land-related bioenergy, that is, excluding the bioenergy potential of the hydrosphere, in particular of the oceans.

In quantifying the estimated bioenergy potential, units of primary energy are used, that is, we leave it unspecified whether biomass is converted into transportation fuel such as alcohol, into electricity, or into any other form of final energy. To account for the uncertainties a high and a low potential was used. The estimation of bioenergy potential was made for the entire globe, disaggregated into eleven world regions (Fig. 1).

Estimates are based on a classification of total land into four major land-use categories: arable land, grassland, forests and "other" land. This allocation is exhaustive, i.e., it leaves no land unclassified. Total land area throughout the time horizon (1990-2050) is constant, that is, no significant additions or losses of the landmass are assumed. Land use changes over time, leading to increasing or decreasing sizes of land categories. The relation between these land classes and the five bioenergy categories - crop residues, energy crops, wood from forests and forest residues, 
Table 1

Land classes and bioenergy categories used for the estimate of bioenergy potentials

\begin{tabular}{ll}
\hline Land category & Bioenergy category \\
\hline Arable land & Crop residues \\
Grassland (incl. pastures, & All kinds of biomass, \\
woodland, and shrubs) & e.g., energy crops \\
Forests & Wood from forests and \\
& forest residues \\
Other land & None \\
None & Animal waste \\
None & Municipal waste \\
\hline
\end{tabular}

animal waste, and municipal waste - is summarised in Table 1.

The first three land-use categories, namely, arable land, grasslands and forests, correspond one-to-one to three bioenergy categories. No land-use class corresponds to animal waste, which is calculated from an energy balance of animal husbandry. The same holds for the energy potential of municipal waste, which is derived from projections of urban population and GDP per capita [2]. "Other land" includes urban areas, protected land, and unused areas such as glaciers, barren land and deserts, and is therefore assumed to have no additional bioenergy potential.

\section{Input data and assumptions}

\subsection{Land-use changes}

The most comprehensive and most readily available source of land-use data for the base year 1990, was FAO [3]. From this base, land-use changes for each of the eleven world regions between 1990 and 2050 were assumed to follow IIASA's Basic Linked System of Models, a business-as-usual (BLS-BAU) global agricultural scenario of overall economic and agricultural development [1]. That scenario includes the quantification of food supply and demand of a world population that increases from 5.3 billion in 1990 to over 10 billion in 2050 . A key result of the scenario calculations is that a mere $12.5 \%$ increase of arable land over 60 years is required to grow the additional crops. Most of the additional food supply comes from increased production per hectare of arable land, which increases at an average annual rate of $1.1 \%$ [4]. In the scenario, the additional arable land comes in approximately equal lots from forests and from grassland as described in detail in a study of land cultivation potential [5]. Use of cultivated land stays nearly constant in developed countries and increases by $20 \%$ in developing countries, though with great variations among regions. Overall, in the BLS-BAU scenario, the net additions to cultivated land between 1990 and 2050 amount to 180 million hectares. For comparison, a recent study by the UN Food and Agriculture Organization projects that arable-land use in developing countries may increase by 120 million hectares between $1995 / 1997$ and 2030 . This increase equals $7.4 \%$ of global arable land estimated for 1995/1997 [20]. Between 1961/1963 and 1995/1997, it is estimated that cultivated land increased by some 265 million hectares [20]. For many reasons, e.g., slowing population growth, limited availability of resources, technological progress, and saturation of food demand, it is argued that conversion of land for agriculture will continue to slow (as it has in the past). Globally, new cultivation leads to a $3 \%$ reduction of grasslands and forests in the year 2050. No attempt was made to project conversion from grassland into forest area (afforestation or reforestation) or vice versa. Since we are mainly concerned with the total bioenergy potential, minor alterations in land allocation concerning only the forests and grassland are therefore insignificant for the results. The resulting land uses for 1990 and for 2050 are tabulated in Table 2.

\subsection{Crop residues}

Crop residues are an important source of fodder and energy. Important residues are the haulmes of grain legumes, the stalks of sorghum, maize and millet, as well as straw from rice, wheat, barley, and oat. Quantities that may be available - assuming sustainable practices - have been estimated by applying a residue factor and a corresponding utilisation coefficient to crop yields. For concepts and typical examples, see $[21,22]$. The bioenergy potential of crop residues was calculated separately for five crop groups: wheat, rice, other grains, protein feed, and other food crops. For each, a residue factor determines the ratio between total above-ground biomass and the primary food produce. In a second step, an "availability fraction" determines those parts of the residues that are considered 
Table 2

Land uses in 1990 and in 2050 in billion $\left(10^{9}\right)$ hectares. "Other land" and "Total land" are the same in both years

\begin{tabular}{lllllllllllll}
\hline & & AFR & CPA & EEU & FSU & LAM & MEA & NAM & PAO & PAS & SAS & WEU \\
\hline Arable & 1990 & 0.24 & 0.14 & 0.05 & 0.23 & 0.16 & 0.04 & 0.23 & 0.06 & 0.06 & 0.20 & 0.11 \\
& 2050 & 0.33 & 0.14 & 0.05 & 0.24 & 0.24 & 0.05 & 0.24 & 0.06 & 0.07 & 0.22 & 0.10 \\
Forests & 1990 & 0.62 & 0.18 & 0.04 & 0.82 & 0.89 & 0.20 & 0.65 & 0.14 & 0.24 & 0.08 & 0.12 \\
& 2050 & 0.57 & 0.18 & 0.04 & 0.82 & 0.84 & 0.20 & 0.65 & 0.14 & 0.23 & 0.08 & 0.12 \\
Grassland & 1990 & 0.72 & 0.53 & 0.02 & 0.33 & 0.59 & 0.34 & 0.27 & 0.43 & 0.01 & 0.05 & 0.09 \\
& 2050 & 0.69 & 0.53 & 0.02 & 0.32 & 0.56 & 0.34 & 0.26 & 0.43 & 0.01 & 0.03 & 0.11 \\
Other land & & 0.66 & 0.35 & 0.01 & 0.81 & 0.38 & 0.74 & 0.69 & 0.20 & 0.10 & 0.13 & 0.13 \\
Total land & & 2.24 & 1.20 & 0.12 & 2.19 & 2.02 & 1.32 & 1.84 & 0.83 & 0.41 & 0.46 & 0.45 \\
\hline
\end{tabular}

Table 3

Bioenergy potential of crop residues per world region, gigajoules per hectare of cultivated land

\begin{tabular}{rrrrrrrrrrrr}
\hline & AFR & CPA & EEU & FSU & LAM & MEA & NAM & PAO & PAS & SAS & WEU \\
\hline 1990 & 6.6 & 23.9 & 14.9 & 9.1 & 9.7 & 12.0 & 16.2 & 5.2 & 10.2 & 17.4 & 14.4 \\
2000 & 8.2 & 27.6 & 15.3 & 9.3 & 11.3 & 15.2 & 17.4 & 6.2 & 12.6 & 19.6 & 15.8 \\
2010 & 9.4 & 30.5 & 15.7 & 9.6 & 13.0 & 18.3 & 18.5 & 7.1 & 14.8 & 20.7 & 16.8 \\
2020 & 10.6 & 33.6 & 16.5 & 10.1 & 14.5 & 21.7 & 19.9 & 8.0 & 17.0 & 21.3 & 18.0 \\
2030 & 11.8 & 35.0 & 16.6 & 10.1 & 15.6 & 23.9 & 20.4 & 8.6 & 19.1 & 22.8 & 18.8 \\
2040 & 13.4 & 36.6 & 17.9 & 10.9 & 16.9 & 27.1 & 21.2 & 9.8 & 20.8 & 25.2 & 20.3 \\
2050 & 14.8 & 37.9 & 18.4 & 11.2 & 17.8 & 29.0 & 21.0 & 10.8 & 22.1 & 26.9 & 21.5 \\
\hline
\end{tabular}

potentially available for energy use. The resulting residues for energy use are then converted into energy units, and further into yield rates per hectare of arable land. The calculated yield rates for each of the eleven world regions are summarised in Table 3.

Yields in each of the 11 world regions are a function of soil quality, climate, water availability, and the crop. They tend to increase over time as a consequence of general agricultural progress, and they are subject to saturation, that is, growth rates are declining over time. Note that bioenergy yield rates calculated in this way do not increase as fast as crop yields because the progress of agricultural technology also leads to increasing the harvesting index of crops, thereby decreasing the corresponding residue factor.

\subsection{Bioenergy from grassland}

The annual bioenergy production on grassland in 1990 in each of the world regions was estimated as a function of climate conditions and land characteristics. Raw data on climate conditions was taken from New et al. [6]. Land characteristics include informa- tion on soil type [7] and on terrain shapes [8]. Aggregate land cover information was derived from EROS [9]. To map the grid data onto the 11 world regions, dry-matter yields were estimated using a recent implementation of FAOs agro-ecological zones methodology (see Fischer et al. [10]). For the assessment of rain-fed land productivity, a water-balance model is used to quantify the beginning and duration of the period when sufficient water is available to sustain crop growth. Soil moisture conditions together with other climate characteristics (radiation and temperature) are used in a simplified and robust crop growth model to calculate potential biomass production and yield.

The calculated potential yields are subsequently combined in a semi-quantitative manner with a number of reduction factors directly or indirectly related to climate (e.g., pest and diseases), and with soil and terrain conditions. The reduction factors, which are successively applied to the potential yields, vary with crop type, the environment (in terms of climate, soil and terrain conditions) and assumptions on level of inputs/management. 
Table 4

Bioenergy potential of grasslands per world region, low and high estimates, gigajoules per hectare

\begin{tabular}{|c|c|c|c|c|c|c|c|c|c|c|c|}
\hline & AFR & CPA & EEU & FSU & LAM & MEA & NAM & PAO & PAS & SAS & WEU \\
\hline 1990 & 52 & 33 & 128 & 31 & 73 & 40 & 53 & 25 & 111 & 70 & 67 \\
\hline 2000 & $56-58$ & $36-37$ & $138-145$ & $33-35$ & $78-81$ & $42-44$ & $57-60$ & $27-28$ & $119-124$ & $75-79$ & $72-75$ \\
\hline 2010 & $60-65$ & $38-41$ & $148-164$ & $36-39$ & $84-91$ & $45-49$ & $61-67$ & $29-31$ & $128-139$ & $81-88$ & $77-84$ \\
\hline 2020 & $64-72$ & $41-46$ & $159-184$ & $38-43$ & $90-101$ & $49-55$ & $66-74$ & $31-35$ & $137-155$ & $87-98$ & $83-94$ \\
\hline 2030 & $69-80$ & $44-51$ & $171-205$ & $41-48$ & $96-113$ & $52-61$ & $70-83$ & $33-39$ & $146-172$ & $93-109$ & $89-104$ \\
\hline 2040 & $73-89$ & $47-57$ & $182-226$ & $44-53$ & $103-125$ & $56-68$ & $75-92$ & $36-43$ & $157-191$ & $99-121$ & $95-116$ \\
\hline 2050 & $79-99$ & $50-63$ & $194-248$ & $47-59$ & $110-139$ & $60-75$ & $80-102$ & $38-48$ & $167-212$ & $106-134$ & $10 \mathrm{I}-128$ \\
\hline
\end{tabular}

In order to ensure that the results relate to production achievable on a sustainable basis, terrain slopes have been excluded when inadequate for the assumed level of inputs/management or too susceptible to topsoil erosion [10]. Dry-matter yields were then converted into specific energy yields.

Comparing these average attainable yields with the potential yields reported by the IPCC Second Assessment Report, shows that possible potential yields are much higher, reaching high values of $400 \mathrm{GJ} / \mathrm{ha}$ in the US and more than $1000 \mathrm{GJ} /$ ha in tropical regions [11]. It was assumed that the bioenergy potential of grassland will grow from the 1990 estimates at rates in the neighbourhood of those of agricultural productivity $(1 \% / y r)$. To reflect the uncertainty behind this assumption, high and low annual growth rates of 0.8 and $1.25 \%$, respectively, were used for the bioenergy potential of grassland. Even the higher rate does not bring the yields near the IPCC values. The resulting low and high yields are summarised in Table 4.

\subsection{Bioenergy potential of the sustainable use of forest products}

The bioenergy potential of forest products in 1990 is based on estimates by Dessus et al. [12]. In their report World potential of renewable energies - actually accessible in the 1990s, the authors estimate specific yields in 1990 and a fraction expressing the availability of forest products for energy uses. The availability numbers assume, among others, that wood energy potential is restricted to distances of less than $200 \mathrm{~km}$ between production and consumption. They also account for the use of some of the growing wood as a raw material. With these authors' numbers for the year 1990 as a basis, the same extrapolation method was used as for grassland to estimate the growth of this potential over time. That is, average annual growth rates of $0.8 \%$ (low estimate) and $1.25 \%$ (high estimate) were assumed. The resulting high and low yields are summarised in Table 5.

\subsection{Animal waste}

The estimation of the bioenergy potential of animal waste was based on animal feed requirements determined in the BLS-BAU scenario. For each world region, a feed balance was established, meeting feed requirements of animals with crops fed directly - according to the BLS-BAU scenario - and subtracting the remainder from the bioenergy potentials of crop residues and grassland yields as calculated above to avoid double counting. From the energy equivalent of all animal-feed inputs, "digestible energy" (i.e., the fraction of energy input actually absorbed by the animals) was subtracted, and the rest defines the bioenergy potential of animal waste.

\subsection{Municipal waste}

The method for estimating the primary energy potential of municipal waste was the same as in the IIASA-WEC study [2]. There it was assumed that with increasing wealth, per-capita municipal waste asymptotically reaches approximately 2.5 tonnes of waste. This is equivalent to $250 \mathrm{~kg}$ oil equivalent or $10 \mathrm{GJ}$ $\left(10^{9} \mathrm{~J}\right) / \mathrm{yr}$.

\section{Results}

The resulting high and low estimates of global bioenergy potential are shown in Fig. 2 . 
Table 5

Average bioenergy potential of the sustainable use of forest products per world region, gigajoules per hectare, ranges

\begin{tabular}{|c|c|c|c|c|c|c|c|c|c|c|c|}
\hline & AFR & $\mathrm{CPA}$ & EEU & FSU & LAM & MEA & NAM & PAO & PAS & SAS & WEU \\
\hline 1990 & 17 & 27 & 19 & 11 & 13 & 12 & 15 & 18 & 19 & 56 & 15 \\
\hline 2000 & $18-19$ & $29-30$ & $21-22$ & $11-12$ & $14-15$ & $12-13$ & $16-17$ & $19-20$ & $21-22$ & $60-62$ & $16-17$ \\
\hline 2010 & $20-21$ & $31-33$ & $22-24$ & $12-13$ & $15-16$ & $13-14$ & $17-18$ & $20-22$ & $22-24$ & $64-69$ & $17-18$ \\
\hline 2020 & $21-24$ & $33-37$ & $24-27$ & $13-15$ & $16-18$ & $14-16$ & $18-21$ & $22-25$ & $24-27$ & $68-77$ & $18-21$ \\
\hline 2030 & $23-27$ & $35-41$ & $26-30$ & $14-16$ & $17-20$ & $15-18$ & $20-23$ & $23-28$ & $25-30$ & $73-86$ & $20-23$ \\
\hline 2040 & $24-29$ & $38-46$ & $28-34$ & $15-18$ & $18-22$ & $16-20$ & $21-25$ & $25-31$ & $27-33$ & $78-96$ & $21-25$ \\
\hline 2050 & $26-33$ & $40-51$ & $29-37$ & $16-20$ & $20-25$ & $17-22$ & $22-28$ & $27-34$ & $29-37$ & $84-106$ & $22-28$ \\
\hline
\end{tabular}
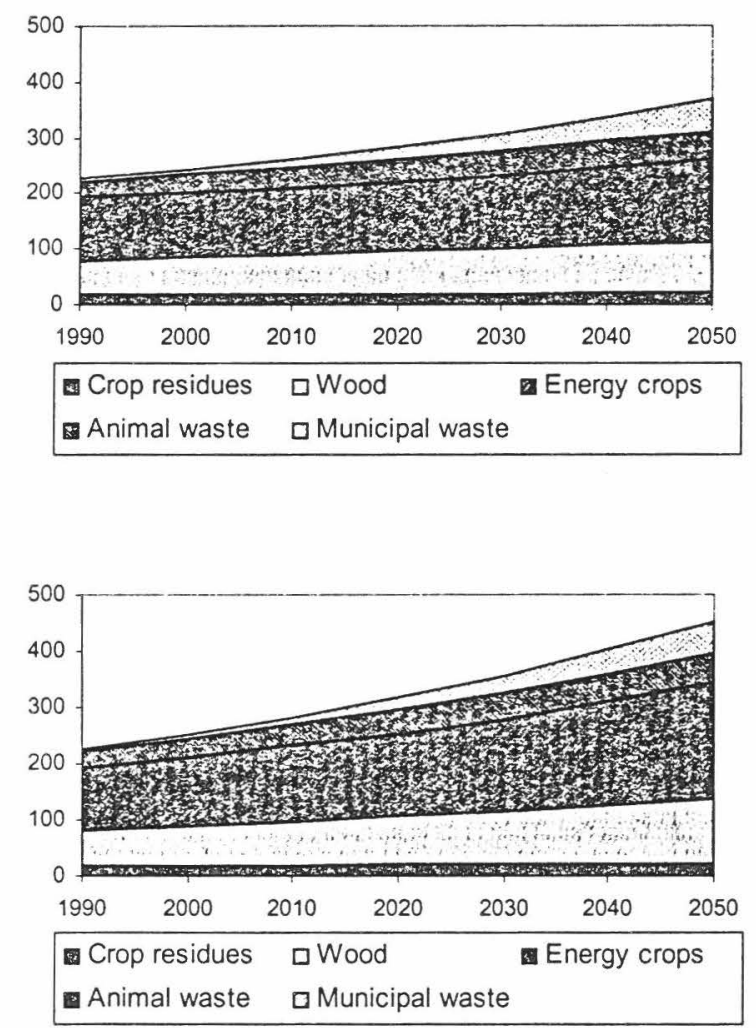

Fig. 2. Global bioenergy potentials, exajoules, disaggregated by category. The panels show the low (left) and the high (right) estimates, respectively.

The total bioenergy potential of the base year, 1990, was estimated at 225 exajoules $\left(10^{18} \mathrm{~J}\right)$ or 5.4 billion $\left(10^{9}\right)$ tons of oil equivalent (Gtoe). For comparison, the actual use of bioenergy in 1990 was 46 exajoules or 1.1 Gtoe. By the year 2050 , this potential was estimated to have grown to between 370 and 450 exa- joules ( 8.8 and $10.8 \mathrm{Gtoe})$. The potential growth occurs in all categories considered. The slowest growth occurs in the "crop residues" category (due to increasing the harvesting index). To put the estimated totals into perspective, the estimated global energy value from photosynthesis is 4000 exajoules [14].

\subsection{Policy aspects}

To actually be able to utilise the growing bioenergy potential of grassland and forests requires policy action, e.g., support in the form of extension programs, economic incentives and $\mathrm{R} \& \mathrm{D}$. In addition, lead times must be taken into consideration. Lead times not only reflect the build-up time of biomass but also technological progress towards a more and more efficient utilisation of the natural energy flows. With respect to final energy demand, the overall efficiency and acceptance of bioenergy depends on appropriate end-use technologies. For a discussion of technology trends in this area, see, for example, [15].

It is beyond the scope of this paper to describe the detailed policy measures that would ensure a high-bioenergy potential and its utilisation. Rather, in the ensuing subsection, we summarise a long-term scenario of global energy supply for which it was assumed that the economic and environmental conditions will make the use of a large fraction of the above-estimated bioenergy potential economic.

\subsection{The IIASA-WEC A3 scenario}

Of the six scenarios of global primary energy supply described in the IIASA-WEC study [2], the scenario with the highest absolute contribution of bioenergy is scenario A3. Other broad characteristics 


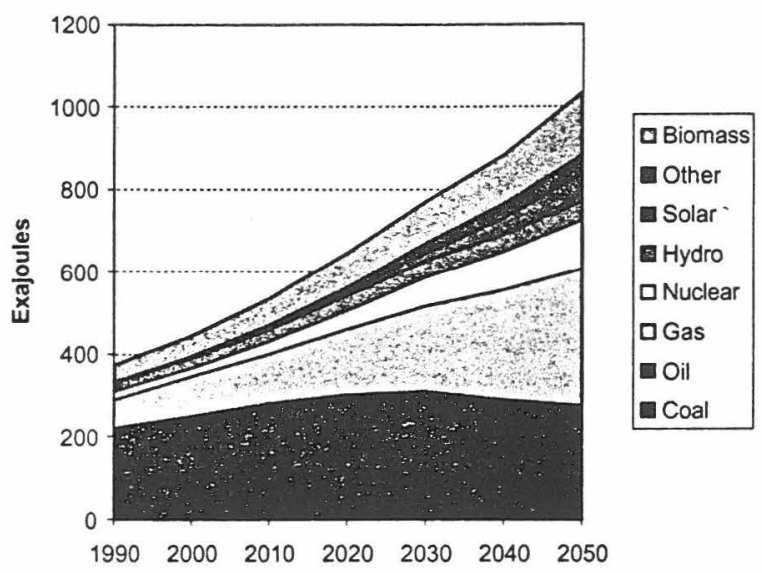

Fig. 3. Global primary energy supply in the IIASA-WEC Scenario 43.

of this scenario include high economic growth, a continuation of rapid technological development, and the assumption of fossil energy resources in the middle range of existing long-term estimates. About bioenergy, it is assumed that technological progress of its production and use will, for example, allow methanol produced using the lower-cost part of the bioenergy potential compete successfully with fossil-based motor fuels after the year 2020. No carbon tax or greenhouse gas emission limit was assumed.

Readers interested in more details concerning assumptions, results, and the path between them are encouraged to refer to [2] and supporting publications for more information on the IIASA-WEC A3 scenario. Here, we just summarise the development of global energy supply as portrayed by that scenario (see Fig. 3). In the year 2050, bioenergy contributes 153 exajoules to global primary energy supply, that is, it would utilise approximately $50 \%$ of our low estimate. In our opinion, this fraction of one-half characterises well the extent to which our estimates describe an economic potential and to which extent they describe a "sub-economic" technical potential. To summarise: the scenario and the estimated potential, taken together, express that fairly favourable but not extreme assumptions (such as high carbon taxes) may lead to bioenergy contributing more than 150 exajoules to global primary energy supply by the year 2050. Such a contribution will be consistent with a scenario of global food production that makes compa- rable assumptions about global economic growth and technological developments.

In environmental terms, a major result of the IIASA-WEC A3 scenario is a significant reduction of the carbon intensity, "decarbonization", of the global energy system. Global energy-related $\mathrm{CO}_{2}$ emissions rise from $6 \mathrm{GtC}$ ( $10^{9}$ tonnes of carbon) in 1990 by no more than $50 \%$ (to $9 \mathrm{GtC}$ ) in 2050 . In the longer-term future, until the year 2100 , the $\mathrm{A} 3$ scenario is the only one of the three high-growth IIASA-WEC scenarios in which atmospheric $\mathrm{CO}_{2}$ concentrations remain below 550 parts per million by volume (that is, twice the pre-industrial level), which is often used as a reference concentration goal.

\subsection{Other studies and results}

To help place the presented estimates of global bioenergy potentials, they are compared in Table 6 with those reported by other authors.

Table 6 distinguishes between scenarios and potentials. In scenarios, bioenergy is assumed to be competitive - at least under the set of circumstances assumed to prevail in a scenario. With the major exception of Dessus et al. [12], who estimated a "competitive" potential of bioenergy, scenario numbers tend to be smaller than potentials. Not surprising, more bioenergy is used in low-carbon emission scenarios. A notable exception is the Greenpeace fossil-free energy scenario (FFES) [16], which projects low-bioenergy shares. This is explained by the generally low-energy demands and the high shares of solar and aeolic (wind) energy in primary energy supply in FFES. Another important factor is the point in time for which an estimate is made. The further in the future the higher the estimate. Strict comparability of all total potentials is difficult to establish because so many different assumptions go into each scenario and into each estimation of bioenergy potentials. In our opinion, specific potentials offer a better basis for the comparison of different studies, and we therefore emphasised bioenergy yields per hectare-year throughout our estimation. A computer program is available from the authors that allows users to quantify their own assumptions and calculate the resulting estimates of global and world-regional bioenergy estimated in a manner consistent with the global food and agricultural scenarios developed at IIASA. 
Table 6

Selected global bioenergy supply scenarios and/or potentials, exajoules

\begin{tabular}{|c|c|c|c|}
\hline \multicolumn{2}{|c|}{ Bioenergy } & \multirow[b]{2}{*}{ Year } & \multirow[b]{2}{*}{ Authors } \\
\hline Scenario & Potential & & \\
\hline & 93 & 1990 & Dessus [12] \\
\hline \multirow[t]{3}{*}{91} & & 2030 & Greenpeace $[16]$ \\
\hline & 93 & - & $\begin{array}{l}\text { Woods, J. and Hall, D.O. Bioenergy for development- } \\
\text { Technical and environmental dimensions, FAO Environ- } \\
\text { ment and Energy Paper 13, Food and Agricultural Orga- } \\
\text { nization of the United Nations, Rome, Italy (1994) }\end{array}$ \\
\hline & 126 & 2020 & Dessus $[12]$ \\
\hline $140-235$ & & 2100 & Kusumikawa and Mori [17] \\
\hline 145 & & 2025 & Johansson et al. [18] \\
\hline 153 & & 2050 & IIASA-WEC [2] \\
\hline 181 & & 2100 & Greenpeace [16] \\
\hline 181 & & 2050 & Leemans et al. [19] \\
\hline 193 & & 2100 & $\begin{array}{l}\text { Lashof, D.A. and Tirpak, D.A. Policy Options for Stabi- } \\
\text { lizing Global Climate: Draft Report to Congress, US En- } \\
\text { vironmental Protection Agency, Washington, D.C. (1990) }\end{array}$ \\
\hline 200 & & 2050 & Johansson et al. [18] \\
\hline $207-221$ & & 2060 & $\begin{array}{l}\text { Shell. The Evolution of the World's Energy System, Shell } \\
\text { International Limited, Group External Affairs, SIL Shell } \\
\text { Centre, London (1996) }\end{array}$ \\
\hline $292-317$ & & 2060 & $\begin{array}{l}\text { Yamamoto H., Yamaji, K., and Fujino, J. Bioenergy in } \\
\text { Global Energy Systems in the Future - Considering } \\
\text { Land Use Competitions and Energy Resource Constraints, } \\
\text { paper presented at the IAEE } 21 \mathrm{st} \text { Annual International } \\
\text { Conference, May 13-16, 1998, Quebec City, Canada }\end{array}$ \\
\hline 315 & & 2100 & IIASA-WEC [2] \\
\hline 331 & & 2100 & Leemans et al. [19] \\
\hline & $350-450$ & 2050 & This study \\
\hline & $338-675$ & - & Lashof, D.A. and Tirpak, D.A. (1990) (as abore) \\
\hline
\end{tabular}

\section{Acknowledgements}

The CRU Global Climatology data has been supplied by the Climate Impacts LINK Project (UK Department of the Environment Contract EPG 1/1/16) on behalf of the Climate Research Unit, University of East Anglia. Valuable comments have been received from our colleagues Ger Klaassen, Alan McDonald, Harrij van Velthuizen, and David Victor.

\section{References}

[1] Fischer G, Frohberg K, Parry ML, Rosenzweig C. In: Downing ThE, editor. Climate change and world food security. NATO ASI Series, vol. I. Berlin: Springer, 1996. p. 37.

[2] Nakićenović N, Grübler A, McDonald A. editors. Global energy perspectives. Cambridge, UK: Cambridge University Press, 1998.
[3] FAO FAOSTAT Statistics Database, 1999. On-line database: http://www.faostat.fao.org/.

[4] Fischer G. Simulating the conventional development paradigm with IIASA's BLS. Proceedings of the United Nations Global Modeling Forum for Sustainable Development. UNU, Tokyo, Japan, March, 1997.

[5] Fischer G, Heilig G. Population momentum and the demand on land and water resources. Philosophical Transactions of the Royal Society of London. Series B 1997;352:869-89.

[6] New MG, Hulme M, Jones PD. Representing 20th century space-time climate variability. Development of a 1961-1990 mean monthly terrestrial climatology http:// www.cru.uea.ac.uk/link, 1998.

[7] FAO. Digital soil map of the world and derived soil properties (version 3.5). CD-ROM, Rome: FAO, 1995.

[8] EROS Data Center. Global 30 arc-second digital elevation model, 1998 http://edcwww.cr.usgs.gov. Anonymous ftp access edcftp.cr.usgs.gov.

[9] EROS Data Center. Land cover characteristics database, Version 1.2, $1998 \mathrm{http} / / /$ edcwww.cr.usgs.gov. Anonymous ftp access edcftp.cr.usgs.gov. 
[10] Fischer G, van Velthuizen HT, Nachtergaele FO. Global agro-ecological zones assessment: http://www.iiasa.ac.at/ Research/LUC/GAEZ/index.htm.

[11] IPCC (Intergovernmental Panel on Climate Change). In: Watson RT, Zinyowera MC, Moss RH. editors. Climate Change 1995 - Impacts, Adaptations and Mitigation of Climate Change: Scientific-Technical Analyses, Contribution of Working Group II to the Second Assessment Report of the Intergovernmental Panel on Climate Change. Cambridge, UK: Cambridge University Press, 1996.

[12] Dessus B, Devin B, Pharabod F. World potential of renewable energies. la Huille Blanche/No. 1, Paris, 1992.

[13] Fischer G, Frohberg K, Keyzer MA, Parikh KS. Linked national models: a tool for international food policy analysis. Dordrecht, The Netherlands: Kluwer Academic Publishers, 1988.

[14] Hall DO, Rosillo-Calle F, Williams RH, Woods J. In: Johansson TBJ, Kelly H, Reddy AKN, Williams R, editors. Biomass for energy: supply prospects. Renewables for fuels and Electricity. Washington, DC: Island Press, 1993.

[15] Moreira et al. Biomass energy: key issues and priority needs. Conference Proceedings. International Energy Agency, Paris, France, 1997.

[16] Greenpeace (Boyle S.) Towards a fossil free future - the technical and economic feasibility of phasing out global fossil fuel use. Greenpeace International, London, 1993.
[17] Kusumikawa J, Mori S. Development and analysis of a world energy-economic-environment model including the forestation option, Science. University of Tokyo, 1998.

[18] Johansson TBJ, Kelly H, Reddy AKN, Williams R. In: Johansson TBJ, Kelly H, Reddy AKN, Williams R, editors. Renewable fuels and electricity for a growing world economy: defining and achieving the potential. Renewables for fuels and electricity. Washington, DC: Island Press, 1993.

[19] Leemans R, van Amstel A, Battjes C, Kreileman E, Toet $A$. The land cover and carbon cycle consequences of large-scale utilizations of biomass as an energy source. Global Environmental Change 1996;6(4):335-58.

[20] FAO, Agriculture: Towards 2015/30, Technical Interim Report, Global Perspective Studies Unit, FAO, Rome, 2000.

[21] FAO, Agro-ecological land resources assessment for agricultural development planning, A case study of Kenya, Technical Annex 5, Lifestock productivity, FAO, Rome, 1991.

[22] UNDP/SSTC/FAO/SLA, Land resources, use and productivity assessment in China, Project CPR/87/029, Technical annex Vol. 4, Assessment of lifestock production potential, United Nations Development Program, State Science and Technology Commission of the Peoples Republic of China, UN Food and Agriculture Organization, State Land Administration the Peoples Republic of China, Beijing, 1994. 



\section{Ordering Information}

Orders must include the publication number and should be sent to the Publications Department, International Institute for Applied Systems Analysis, A-2361 Laxenburg, Austria.

Telephone: +432236807

Telefax: +43223671313

E-mail: molina@iiasa.ac.at

A full list of IIASA publications is available at www.iiasa.ac.at 
International Institute for Applied Systems Analysis

Schlossplatz 1, A-2361 Laxenburg, Austria

7 Tel: +432236807 Fax: +43 223671313

IIASA www.iiasa.ac.at 